\title{
The Effectiveness of Training on Auscultation of Heart with a Simulator of Cardiology in Medical Students
}

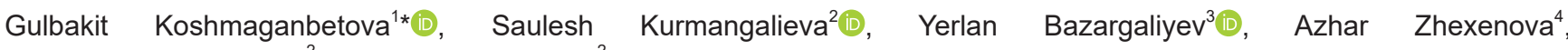 \\ Baktybergen Urekeshov ${ }^{2}$, Madina Azhmuratova ${ }^{2}$ \\ ${ }^{1}$ Department of Master's and Doctoral Studies, West Kazakhstan Marat Ospanov Medical University, Aktobe, Kazakhstan; \\ ${ }^{2}$ Department of Microbiology, Virology and Immunology, West Kazakhstan Marat Ospanov Medical University, Aktobe, \\ Kazakhstan; ${ }^{3}$ Department of Internal Diseases, West Kazakhstan Marat Ospanov Medical University, Aktobe, Kazakhstan; \\ ${ }^{4}$ Department of Pathological Physiology, West Kazakhstan Marat Ospanov Medical University, Aktobe, Kazakhstan
}

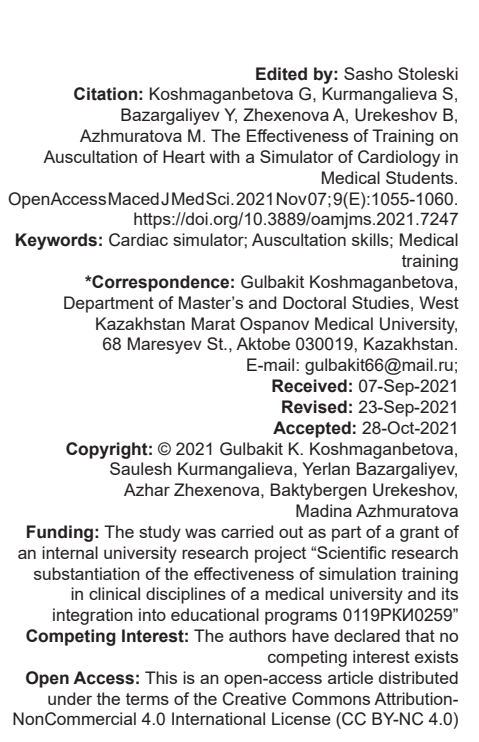

Abstract

AIM: The purpose of this study was to determine whether the training module with a simulator of cardiology improves auscultation skills in medical students.

METHODS: Medical students of the $3^{\text {rd }}$ year after completing the module of the cardiovascular system of the discipline "Propedeutics of internal diseases," passed a $2 \mathrm{~h}$ or $4 \mathrm{~h}$ training module in clinical auscultation with retesting immediately after the intervention and in the $4^{\text {th }}$ year. The control group consisted of the $4^{\text {th }}$ year medical students who had no intervention.

RESULTS: The diagnostic accuracy in $2 \mathrm{~h}$ training was $45.9 \%$ versus $35.3 \%$ in $4 \mathrm{~h}$ training, $\mathrm{p}<0.001$. The use of a cardiosimulator significantly increased the accurate detection of mitral regurgitation immediately after training on a simulator (more than $73 \%$ ), $p<0.001$. The next academic year, regression was observed in the diagnostic accuracy of mitral insufficiency in the intervention group after 6 months of observation by $4 \%$. The auscultation skills of students at the bedside of real patients did not increase after training on a simulator: The accuracy of diagnosis of the auscultatory picture of the defect was equally low in the intervention group and the control group $(35.0 \%$ vs. $30.8 \%, p=0.651)$

CONCLUSION: Two hours training was more effective than $4 \mathrm{~h}$ training. After training on cardiac auscultation using a patient's cardiological simulator, the accuracy rate was low in a situation close to the clinical conditions and in a clinic on a real patient.

\section{Introduction}

Auscultation of the heart is one of the important skills of physical examination of patients in the diagnosis of various heart diseases. Simulation has been identified as a potential way to improve physical examination methods in medical education [1].

Despite many years of experience using cardiac simulators in medical education, the data are contradictory in numerous studies on simulation training. There are studies which show some improvement in heart auscultation skills among medical students after using a cardiopulmonary simulator [2], [3]. A metaanalysis of 13 comparative studies showed that simulation-based learning with auscultation of the heart was effective [4]. The heart auscultation curriculum, consisting of a computer textbook and a heart disease simulator, improved auscultation skills in trained students compared to untrained ones [5]. The use of the Kyoto-Kagaku K Plus simulator in training improved Student's t-test auscultation skills in a Bernardi et al. study [6]. In other studies, weak cardiological examination skills were recorded in medical students using cardiac simulators [7], [8], computer training programs [9], and at the patient's bedside [10], [11]. In several well-planned randomized trials, no significant differences were found between heart simulations and other interventions [12], [13], [14], [15]

Thus, it remains unclear whether there is any intervention that can be applied at an early stage of medical training, contributing to the improvement of heart auscultation skills.

There were no studies conducted at medical universities of the Republic of Kazakhstan aimed at studying the effectiveness of simulation training, its place in educational programs, the selection of specific 
teaching and assessment methods, and the necessary time to develop one or another skill.

\section{Purposes}

The purpose of the study was determining whether the cardiosimulation training improves auscultation skills in the $3^{\text {rd }}$ year students of West Kazakhstan Medical University (WKMU).

\section{Materials and Methods}

\section{Participants and simulators}

A total of one hundred and fifteen $3^{\text {rd }}$ year students of the general medicine faculty (77 students in a $2 \mathrm{~h}$ course and 38 students in a $4 \mathrm{~h}$ course of study) WKMU took part in a heart auscultation training using a heart disease simulator (KAF990, China). Ethical approval was obtained from the Local Ethics Committee of WKMU.

The training consisted of $2 \mathrm{~h}$ and $4 \mathrm{~h}$ practical classes (one academic hour is $50 \mathrm{~min}$ ) in compliance with standard procedures (the presence of a dressing gown and a phonendoscope), including safety measures. Students were divided into groups of 6-8 people. Each group visited the practical skills center of WKMU for auscultation of the heart. The training was held in the $6^{\text {th }}$ semester of the 2018-2019 academic year after passing the module of the cardiovascular system of the discipline "Propedeutics of internal diseases." Simulation training at our university is not included in the compulsory educational program. The study involved students who agreed to additional training. The study was carried out as part of a grant of an intrauniversity research project "Research substantiation of the effectiveness of simulation training in the clinical disciplines of a medical university and its integration into educational programs." Two certified teachers conducted heart auscultation training. After a short introduction, the teacher gave a minilecture on heart auscultation skills, heart sounds, including acquired heart murmurs with four heart defects (aortic valve stenosis [AS], mitral valve stenosis [MS], aortic insufficiency [AI], and mitral insufficiency [MI]).

Each student practiced on the simulator after mini-lecture led by the teacher. The KAF 990 simulator is a human torso dummy with four small built-in speakers in the aorta, pulmonary, tricuspid, and mitral valves. It provides 82 variations of heart sounds and sounds. Students used a conventional phonendoscope for the KAF 990 simulator.

Each student passed three different auscultation tests using the simulator after practicing to recognize heart sounds and heart sounds using the KAF
990 simulator. Students were informed that the grades received in the framework of this training will not have any relation to the overall performance of the course. All the students agreed to participate in the study. Vices were divided into two categories: "Insufficiency" ( $\mathrm{Ml}$ and $\mathrm{Al}$ ) and "Stenosis" (MS and AS). The first test consisted of two parts. Students were informed that the vices were from the appropriate category. (1) Students listened to two vices from the "Insufficiency" category at random, tried to identify each of the two, and wrote down their answers; (2) students listened to two heart defects from the "Stenosis" category in random order and tried to identify an auscultatory picture of the disease. Immediately after the first test, the teacher conducted a debriefing, where he gave students feedback so that they could confirm which heart sounds or murmurs inherent in a particular defect they correctly identified and which ones did not, before proceeding to the second test.

The second and third tests, students were not informed about the category, listened and tried to identify each of the four defects in a random order, and wrote down their answers. Immediately after the second and third tests, the teacher also gave feedback to students.

At the $7^{\text {th }}$ semester of the 2019-2020 academic year, the second stage of research was conducted - a controlled study on a real patient. The $4^{\text {th }}$-year medical students ( $\mathrm{n}=18$ out of 77 ) who participated in $2 \mathrm{~h}$ simulation training in the $3^{\text {rd }}$ year (main group) and students $(n=19)$ who did not go through training (control group) examined a real patient with mitral regurgitation. Students presented their results to an examiner, who then assessed heart auscultation skills. The expert was a practicing cardiologist who studied and verified the clinical data in a patient. Each student was tested on the same patient and evaluated by the same examiner, which means a higher degree of consistency and objectivity in the assessment.

\section{Statistical analysis}

Data were analyzed using the program Statistica 10 (Stat Soft, USA).

(1) Comparison of the accuracy of determination of each of the four heart defects in the first, second, and third tests in the group of $2 \mathrm{~h}$ training on a simulator using the McNemar criterion $\chi^{2} . p<0.05$ was considered statistically significant.

Comparison of the accuracy of determination of each of the four heart defects in the first, second, and third tests in the $4 \mathrm{~h}$ training group on a simulator using McNemar criterion $\chi^{2}$. $p<0.05$ was considered statistically significant. Comparison of the accuracy of determination of each of the four heart defects in the first, second, and third tests in the $2 \mathrm{~h}$ group and 
in the $4 \mathrm{~h}$ group on a simulator using the Pearson $\chi^{2}$ criterion. $p<0.05$ was considered statistically significant.

Comparison of the accuracy of determining heart disease in a real patient in the intervention group (training on the simulator) with the control group (without training on the simulator) using the Pearson $\chi^{2}$ criterion. $p<0.05$ was considered statistically significant.

\section{Results}

Diagnostic accuracy in three tests in a $2 \mathrm{~h}$ training is presented in Figure 1.

The overall accuracy in the $2 \mathrm{~h}$ training was $43.3 \%$ in the first test, $44.8 \%$ in the second, and $49.5 \%$ in the third test, the difference was statistically insignificant $(p=0.4425)$.

As can be seen from the data presented, most accurately the students in the third test determined the Ml. Hence, if only 26 students out of 77 correctly identified this defect in the first and second tests, then in the third test, there are already 60 students $(p=0.00001)$ (Figure 1).

In the first test with informing, Al was correctly identified by 59 out of 77 students, then in the third test, only 30 students were already identified $(76.6 \%$ vs. $44.1 \%$, $p=0.02064)$, that is, 19 students, when they were not told the category, could not determine this defect (Figure 1).
If 56 of 77 students (73.7\%) were incorrectly determined in the first test, the MS showed a decrease in the number of incorrect answers to $61 \%(p=0.00002)$ (Figure 1).

As for AS, in the first test, 28 out of 77 students correctly identified this defect, while in the second attempt, 52 students $(67.5 \%)$ identified it, but in the third test, there was a statistically significant decrease in accuracy to $36.4 \%(p=0.00019)$ (Figure 1).

The overall accuracy in the $4 \mathrm{~h}$ training was $34.9 \%$ in the first test, $38.15 \%$ in the second, and $32.9 \%$ in the third test, the difference was statistically insignificant $(p=0.861)$.

Diagnostic accuracy in three tests in a $4 \mathrm{~h}$ training is presented in Figure 2.

The highest diagnostic accuracy in the $4 \mathrm{~h}$ training was among students of MI. Hence, if in the first and second tests, 14 out of 38 students were able to correctly identify this defect, then in the third test, already 28 students managed to determine the auscultatory picture inherent in MI ( $p=0.00933)$ (Figure 2).

The accuracy of auscultatory diagnosis of $\mathrm{Al}$ of students statistically significantly decreased by $36.9 \%$ in the third test compared to the first test $(p=0.00112)$, but increased 2 times in comparison with the second (Figure 2). There was also a marked statistically significant decrease in the percentage of students' correct answers when determining AS between the $2^{\text {nd }}$ and $3^{\text {rd }}$ tests $(65.8 \%$ vs. $15.8 \%$, respectively, $\mathrm{p}=0.00535$ ) (Figure 2).

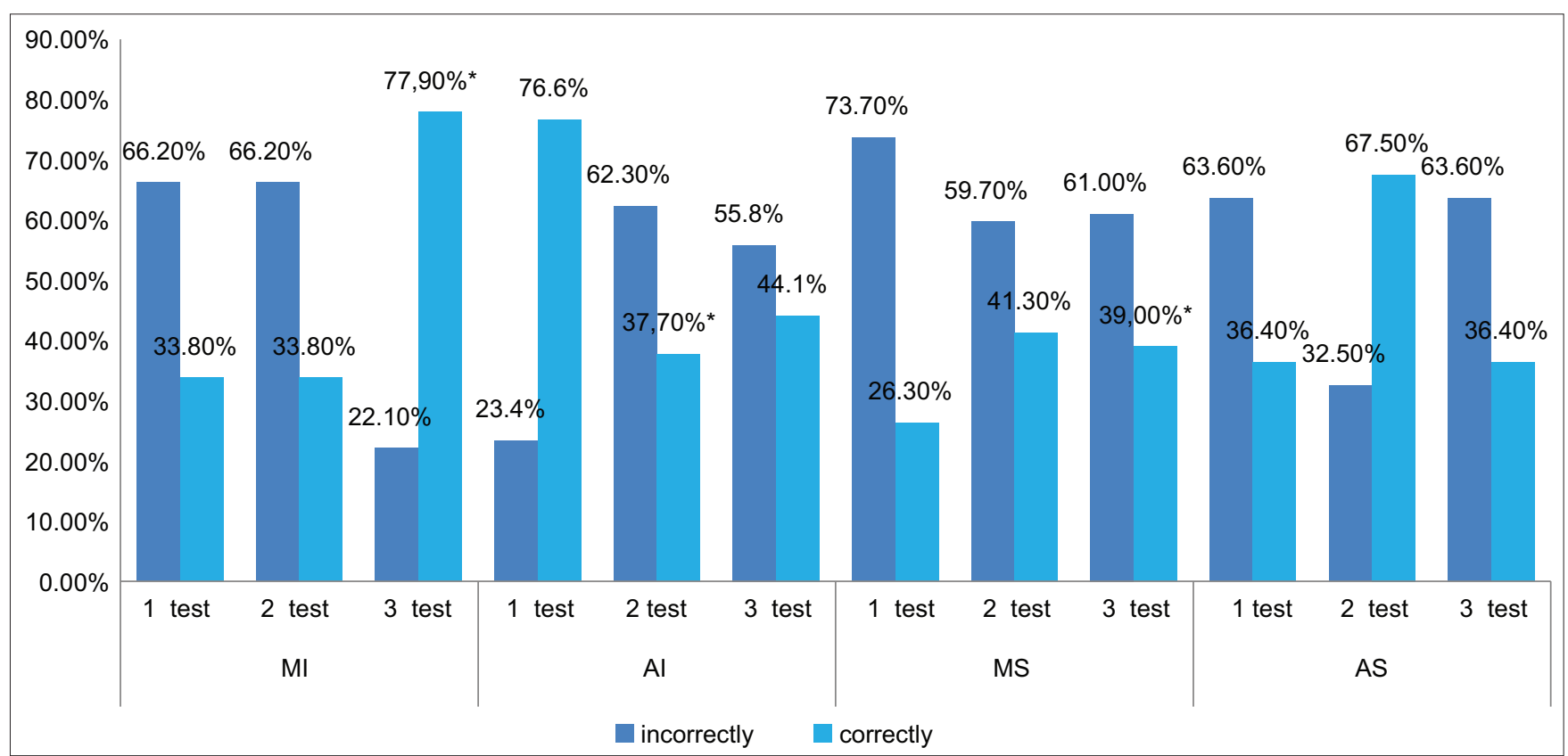

Figure 1: The percentage of correct and incorrect answers of students in one test (with informing about the category), in two and three tests (without informing about the category) in a $2 \mathrm{~h}$ training. *Statistically significant differences between the $1^{\text {st }}$ and $3^{\text {rd }}$ tests for MI ( $\chi^{2} \mathrm{McNemar}$ 19.4, $s s=1, p=0.00001)$, for Al ( $\chi^{2}$ McNemar $\left.5.4 s s=1, p=0.02064\right)$, by MS ( $\chi^{2}$ McNemar $\left.18.3 s s=1, p=0.00002\right)$, between two and three tests by AS ( $\chi^{2}$ McNemar 13.9, ss = 1, $\left.p=0.00019\right)$. MI: Mitral insufficiency, Al: Aortic insufficiency, AS: Aortic valve stenosis, MS: Mitral valve stenosis 


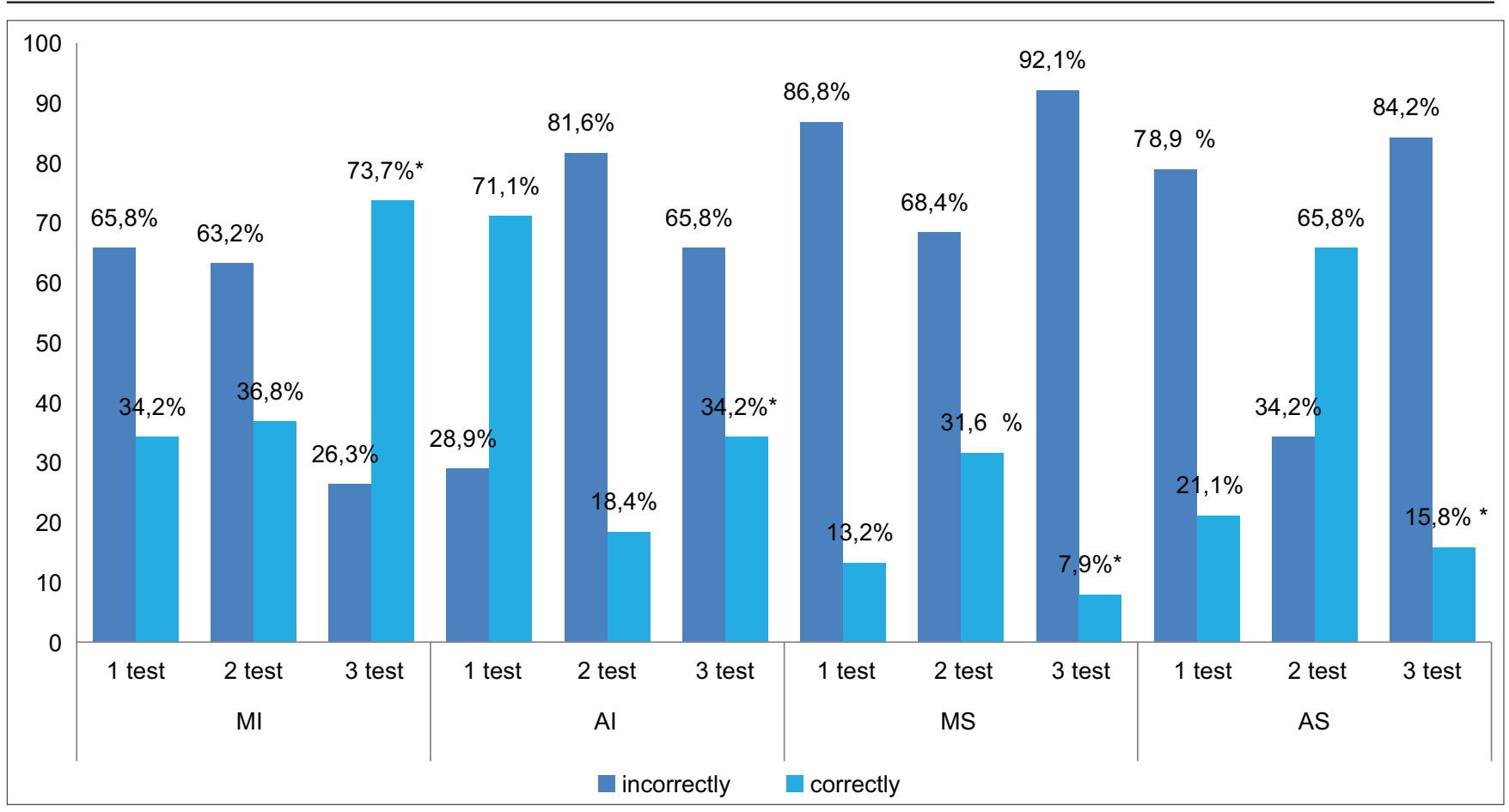

Figure 2: The percentage of correct and incorrect answers of students in the $1^{\text {st }}$ test (with informing about the category), in the $2^{\text {nd }}$ and $3^{\text {rd }}$ tests (without informing about the category) in the $4 \mathrm{~h}$ training. *Statistically significant differences between the $1^{\text {st }}$ and $3^{\text {rd }}$ tests for MI ( $\chi^{2} \mathrm{McNemar} r$ 6.76, $s s=1, p=0.00933)$, one and three tests for $A I$ ( $\chi^{2}$ McNemar 10.62, $\left.s s=1, p=0.00112\right)$, two and three by the AS test ( $\chi^{2}$ McNemar 7.76, $s s=1, p=0.00535)$. MI: Mitral insufficiency, Al: Aortic insufficiency, AS: Aortic valve stenosis, MS: Mitral valve stenosis

The highest average percentage of incorrect answers (82.4\%) was established when students recognized the MS (Figure 2).

Comparison of the accuracy of diagnosis of defects among students in $2 \mathrm{~h}$ and $4 \mathrm{~h}$ trainings revealed statistically significant differences in $\chi^{2}$ Pearson between the second tests for Al $37.6 \%$ versus $18.4 \%(p=0.036)$, between the third tests for MS $38.9 \%$ versus $7.9 \%$ ( $p=0.00053$ ), according to AS $36.36 \%$ versus $15.79 \%$ $(p=0.0229)$.

\section{6 months}

\section{Results of the repeating test after}

Repeated testing in the $4^{\text {th }}$ year in a real patient did not reveal statistically significant differences in the accuracy of diagnosis of $\mathrm{Ml}$ in a real patient between the intervention group and the control group $(35.0 \%$ vs. $30.8 \%, p=0.651)$.

\section{Discussion}

In this study, we examined the effectiveness of training on auscultation of the heart using the KAF 990 cardiac simulator, aimed at acquiring auscultatory heart skills by medical students.

In general, acquiring heart auscultation skills are a difficult task. The gradual deterioration of the quality of education is caused by: time limits, low availability of thematic patients, the severity of the patient's condition, the presence of psychological problems in students when working with a real patient, the direct refusal of patients to communicate with students [15].

We demonstrated that the rate of accuracy of auscultation of the heart decreased in the third test, which was closer to the clinical conditions than the first test. This was mainly due to the incorrect identification of $\mathrm{Al}, \mathrm{MS}$, and Al. These results suggest that one training in cardiac auscultation training using a patient's cardiac simulator may not be enough to acquire the competency necessary for a clinician and that medical students are less likely to correctly identify Al, MS, and Al even right after auscultation training.

The diagnostic accuracy of $45.9 \%$ in $2 \mathrm{~h}$ training and $35.3 \%$ in $4 \mathrm{~h}$ training in our study is not satisfactory. Diastolic murmurs, such as aortic regurgitation and mitral stenosis, are usually a problem for most students in the learning process [7], [16]. In our study, the accuracy of the correct diagnosis of mitral stenosis among all malformations was the lowest in the $4 \mathrm{~h}$ training, while the percentage of correct detection of MI was relatively better among students. There was no significant improvement in the diagnostic accuracy of the MS even after the intervention. The results of our study are consistent with the study of Birdane et al. (2012) and Binka et al. (2016), where students also better recognized systolic murmurs compared to diastolic murmurs [7], [17]. Physical examination has limited ability to evaluate diastolic murmurs, with a sensitivity of only $14-33 \%$ for the diagnosis of aortic 
regurgitation [18], [19]. Modifications to the training will be required to teach auscultation of mitral stenosis noise.

An alternative to long-term repetition of cardiac auscultation in patients, which is undesirable and impossible, is the use of cardiovascular equipment. The using of simple cardiopulmonary simulators as tool of the medical education may be practical, cost effective, and efficient [2].

It is known that repeated intentional repetitive practice with constructive feedback and an increase in the time spent on the study of a simulated cardiac examination have a significant influence on the effectiveness of modeling [20], [21], [22]. This study found that $2 \mathrm{~h}$ training was more effective than $4 \mathrm{~h}$ training, repeated exposure to an expert assessment did not improve students' knowledge, as in the Swamy et al. study (2014) [23].

In the present study, it was found that the use of a simulator in cardiac auscultation training significantly increased the percentage of accurate detection of systolic murmur in MI immediately after training on a simulator (more than 73\%). However, with repeated testing, regression was observed in the diagnostic accuracy of $\mathrm{Ml}$ in the intervention group after 60 months of observation. It was revealed that the auscultation skills of students at the bedside of a real patient did not increase after training on the simulator: The accuracy of diagnosis of the auscultatory picture of the defect was equally low in the intervention group and the control group. Vukanovic-Criley et al. [11] reported that cardiac examination skills do not improve after the $3^{\text {rd }}$ year of study at a medical school and may decline after several years in clinical practice. Therefore, it is extremely important for medical students to acquire competency to identify these abnormal heart sounds and sounds before participating in clinical practice [23].

\section{Conclusion}

Two hour training was more effective than $4 \mathrm{~h}$ training, repeated exposure to an expert assessment did not improve students' knowledge. After training on cardiac auscultation using a patient's cardiac simulator, the accuracy rate was low in a situation close to the clinical conditions and in a clinic on a real patient. This was mainly due to the low level of identification of MS, AI, and AS. One training session using a single cardiological patient simulator may not be enough for medical students to achieve the competency necessary for the clinician. We may have to consider this characteristic of medical students when we provide them with cardiac auscultation training. It is necessary to include modeling in preclinical modules, in particular, in the module of the cardiovascular system, as a mandatory component in training. Training using a cardiopulmonary simulator can be a useful tool for training preclinical medical students, to help translate pre-clinical knowledge into real clinical skills. The results of our research can be a platform for well-planned large-scale studies to study real results after changing the curriculum. Future research should focus on comparing key features of educational design and determining the effectiveness of cardiosimulation.

\section{Limitations}

Our study is not without limitations. The design of this research was quasi-experimental. The selection of participants was carried out by a targeted sampling method, in which participants are selected on the basis of characteristics that will reliably answer of the research question; randomization and blinding were not carried out. The benefits of short simulation training were studied. Only an expert assessment of auscultation skills of students of one medical university was carried out. When conducting a controlled study on a real patient, the sample size was small; only one patient with one defect was tested.

\section{Acknowledgments}

We thank students for voluntary participation in the study. The study was carried out as part of a grant of an internal university research project "Scientific research substantiation of the effectiveness of simulation training in clinical disciplines of a medical university and its integration into educational programs 0119РКИ0259."

\section{References}

1. Cook DA, Hamstra SJ, Brydges R, Zendejas B, Szostek JH, Wang AT, et al. Comparative effectiveness of instructional design features in simulation-based education: Systematic review and meta-analysis. Med Teach. 2013;35(1):e867-98. https://doi.org/ 10.3109/0142159x.2012.714886

PMid:22938677

2. Sword DO, Thomas KJ, Wise HH, Brown DD. A novel and cost-effective method for evaluating cardiopulmonary auscultation skills in student physical therapists. J Allied Health. 2017;46(1):e9-13. PMid:28255599

3. Perlini S, Salinaro F, Santalucia P, Musca F. Simulationguided cardiac auscultation improves medical students clinical skills: The Pavia pilot experience. Intern Emerg Med. 2014;9(2):165-72. https://doi.org/10.1007/s11739-012-0811-z PMid:22767224

4. McKinney J, Cook DA, Wood D, Hatala R. Simulation-based training for cardiac auscultation skills: Systematic review and 
meta-analysis. J Gen Intern Med. 2013;28(2):283-91. https:// doi.org/10.1007/s11606-012-2198-y

\section{PMid:22968795}

5. Butter J, McGaghie WC, Cohen ER, Kaye M, Wayne DB. Simulation-based mastery learning improves cardiac auscultation skills in medical students. J Gen Intern Med. 2010;25(8):780-5. https://doi.org/10.1007/s11606-010-1309-x PMid:20339952

6. Bernardi S, Giudici F, Leone MF, Zuolo G, Furlotti S, Carretta R, et al. A prospective study on the efficacy of patient simulation in heart and lung auscultation. BMC Med Educ. 2019;19(1):275. https://doi.org/10.1186/s12909-019-1708-6

PMid:31337361

7. Birdane A, Yazici HU, Aydar Y, Mert KU, Masifov M, Ulus T, et al. Effectiveness of cardiac simulator on the acquirement of cardiac auscultatory skills of medical students. Adv Clin Exp Med. 2012;21(6):791-8. https://doi.org/10.1016/j. amjcard.2014.01.222

PMid:23457137

8. Sibbald M, McKinney J, Cavalcanti RB, Yu E, Wood DA, Nair P, et al. Cardiac examination and the effect of dual-processing instruction in a cardiopulmonary simulator. Adv Health Sci Educ Theory Pract. 2013;18(3):497-508. https://doi.org/10.1007/ s10459-012-9388-6

PMid:22717993

9. Sverdrup $\varnothing$, Jensen T, Solheim S, Gjesdal K. Training auscultatory skills: Computer simulated heart sounds or additional bedside training? A randomized trial on third-year medical students. BMC Med Educ. 2010;10:3. https://doi. org/10.1186/1472-6920-10-3

\section{PMid:20082701}

10. Favrat B, Pécoud A, Jaussi A. Teaching cardiac auscultation to trainees in internal medicine and family practice: Does it work? BMCMedEduc. 2004;4:5. https://doi.org/10.1186/1472-6920-4-5 PMid:15056393

11. Vukanovic-Criley JM, Criley S, Warde CM, Boker JR, GuevaraMatheus L, Churchill WH, et al. Competency in cardiac examination skills in medical students, trainees, physicians, and faculty: A multicenter study. Arch Intern Med. 2006;166(6):6106. https://doi.org/10.1001/archinte.166.6.610 PMid: 16567598

12. Tuzer $H$, Dinc L, Elcin M. The effects of using high-fidelity simulators and standardized patients on the thorax, lung, and cardiac examination skills of undergraduate nursing students. Nurse Educ Today. 2016;45:120-5. https://doi.org/10.1016/j. nedt.2016.07.002

PMid:27449150

13. Kagaya $\mathrm{Y}$, Tabata $\mathrm{M}$, Arata $\mathrm{Y}$, Kameoka J, Ishii S. Variation in effectiveness of a cardiac auscultation training class with a cardiology patient simulator among heart sounds and murmurs. J Cardiol. 2017;70(2):192-8. https://doi.org/10.1016/j. jjcc.2016.10.011

PMid:27916238
14. Gordon JA, Shaffer DW, Raemer DB, Pawlowski J, Hurford WE, Cooper JB. A randomized controlled trial of simulation-based teaching versus traditional instruction in medicine: A pilot study among clinical medical students. Adv Health Sci Educ Theory Pract. 2006;11(1):33-9. https://doi.org/10.1007/ s10459-004-7346-7

\section{PMid:16583282}

15. Bilello LA, Dubosh NM, Lewis JJ, Hall MM, Fisher J, Ullman EA Fourth-year medical students do not perform a focused physical examination during a case-based simulation scenario. Adv Med Educ Pract. 2018;9:583-8.

PMid:30154677

16. Naumov LB. Heart murmurs auscultation as professional learning problems. Anadolu Kardiyol Derg. 2009;9(3):167-75. PMid:19520649

17. Binka EK, Lewin LO, Gaskin PR. Small steps in impacting clinical auscultation of medical students. Glob Pediatr Health. 2016;3:2333794. https://doi.org/10.1177/2333794×16669013 PMid:27689103

18. Stokke TM, Ruddox V, Sarvari SI, Otterstad JE, Aune E, Edvardsen T. Brief group training of medical students in focused cardiac ultrasound may improve diagnostic accuracy of physical examination. J Am Soc Echocardiogr. 2014;27(11):1238-46. https://doi.org/10.1016/j.echo.2014.08.001 PMid:25216765

19. Kobal SL, Trento L, Baharami S, Tolstrup K, Naqvi TZ, Cercek B, et al. Comparison of effectiveness of hand-carried ultrasound to bedside cardiovascular physical examination. Am J Cardiol. 2005;96(7):1002-6. https://doi.org/10.1016/j. amjcard.2005.05.060

PMid:16188532

20. Issenberg SB, McGaghie WC, Gordon DL, Symes S, Petrusa ER, Hart IR, et al. Effectiveness of a cardiology review course for internal medicine residents using simulation technology and deliberate practice. Teach Learn Med. 2002;14(4):223-8. https:// doi.org/10.1207/s15328015tlm1404_4

PMid:12395483

21. Barrett MJ, Kuzma MA, Seto TC, Richards P, Mason D, Barrett DM, et al. The power of repetition in mastering cardiac auscultation. Am J Med. 2006;119(1):73-5. https://doi. org/10.1016/j.amjmed.2004.12.036

\section{PMid:16431198}

22. Koshmaganbetova GK, Kurmangalieva SS. The effectiveness of using simulation to teach heart auscultation skills in medical students (Literature review). Bull KazNMU. 2018;3:31-7.

23. Swamy M, Sawdon M, Chaytor A, Cox D, Barbaro-Brown J, McLachlan J. A study to investigate the effectiveness of SimMan ${ }^{\circledR}$ as an adjunct in teaching preclinical skills to medical students. BMC Med Educ. 2014;14:231. https://doi. org/10.1186/1472-6920-14-231

PMid:25410815 